A vastly revised and updated version of this preprint is available as a chapter in a book titled: Reorientation of activities and self-environment integration: A new theory of activities. The book is available from https:// www.amazon.com/dp/9357738096.

The International Journal of Indian Psychology ISSN 2348-5396 (Online) | ISSN: 2349-3429 (Print)

Volume 8, Issue 2, April- June, 2020

diip DIP: $18.01 .102 / 20200802$, DOI: $10.25215 / 0802.102$

(http://www.ijip.in

Research Paper

\title{
Multiple activities change intervention, a developing psychosocial tool for severe depression: initial report of cases
}

\author{
Atul Agarwal ${ }^{1 *}$
}

\section{ABSTRACT}

Many depressed individuals are labelled as treatment resistant, refractory, or difficult to treat depression. Such depression is highly disruptive and leads to multiple adverse outcomes in a person's life including marital turmoil, unstable employment, and early mortality. The socalled newer techniques, involving electricity or magnetism - are unproven, costly, not easily available, may lead to harm, and may require surgery and anaesthesia. With no effective treatment modality available, these cases of severe depression become significant, as they reported remarkable recovery with a novel psycho-social intervention called multiple activities change intervention or MACI. A 36-year man Kumar presented with severe depression of 15-years duration. At the time of presentation, he was faced with multiple physical and psychological symptoms, workplace difficulties, and domestic disharmony and violence. He had been taking selective-serotonin-reuptake-inhibitors and lorazepam, and his BDI-II score was 36. MACI was administered that led to sharp reduction in symptoms and other all-round improvements. BDI-II score fell to three, and all psycho-pharmaceuticals were gradually stopped. He stopped considering himself mentally ill. All this and more happened within a space of 100 days. Two other similar cases are being reported.

Keywords: Severe Depression, Multiple Activities Change Intervention, MACI, Recovery from Depression, Psychosocial, Psychotherapy

A novel intervention (multiple activities change intervention or MACI) is being introduced through these case reports. For our purpose, activities include behaviours, thoughts, and feelings.

MACI can be viewed as an intervention that changes multiple activities-and its brief working definition could be: an intervention that empowers the individuals for simultaneously and systematically changing their multiple activities. A MACI empowered person can (and it is hoped that she will) strive to become a better-quality individual throughout her life - and thus multiple dimensions of society would improve. So, we can add to the definition that a MACI empowered person has a lifelong choice but not the obligation to improve herself and become a better-quality individual.

${ }^{1}$ Retired Professor, Nagpur, India

*Responding Author

Received: May 18, 2020; Revision Received: June 20, 2020; Accepted: June 25, 2020

(C) 2020, A. Agarwal; licensee IJIP. This is an Open Access Research distributed under the terms of the Creative Commons Attribution License (www.creativecommons.org/licenses/by/2.0), which permits unrestricted use, distribution, and reproduction in any Medium, provided the original work is properly cited. 
MACI is a bottom-up intervention that has been evolved and updated through first hand clinical experience during my lifetime. I have routinely applied this intervention (or its prior versions) with generally good results and without any adverse effects. Now through this case series, I am trying to introduce this intervention.

\section{Case-1:}

Kumar 36-male, graduate, shift in-charge in a public limited company, presented with severe depression of 15-years duration. He reported multiple physical and psychological symptoms, workplace difficulties, domestic disharmony and violence. He was on selective-serotoninreuptake-inhibitors and lorazepam, and his BDI-II score was 36.

An intervention was applied:

1. Session one was used for history taking and examination. He was taught and asked to practice controlled breathing and relaxation in a corpse posture. He was advised regular physical activity (walking); and control over emotions such as anger, worry, and sexual urges. Antidepressants and lorazepam were continued-and 500 milligrams of paracetamol was advised at bedtime and whenever needed.

2. One week later, during session two, strategic advice was given for forgetting pain related to past events. This was done without going into the details of those events. As more control was being perceived, medium- and long-term targets were to be set, and regular effort was to be gradually initiated to develop skills and competencies needed to achieve those targets. Advice given during session one was to be continued with modifications as needed. The medications were continued.

3. Weekly or fortnightly sessions were conducted largely to assess the progress and to reinforce the advice given during earlier session. During these sessions, antidepressants and lorazepam were gradually withdrawn.

\section{Outcome:}

Eleventh day after the intervention, most symptoms had disappeared and BDI-II score had fallen to three. Another two months later, he stopped all psycho-pharmaceuticals. Another one month later, many more changes had occurred: He no longer considered himself mentally ill. Abusive language and violent behaviour had stopped, and he had started speaking softly to his subordinates. He had been promoted, and he had started reporting to the General Manager Productions. He had joined MBA, and in the evening class he was comfortably interacting with much younger fellow students. He had started taking interest in work-while previously he used to consider work as a burden. He admitted he had never imagined that so much change was possible. Kumar (at the end of 100 days) felt that he had raced above his normal colleagues, who never had any mental illness. Two years later, during a telephonic conversation, he reported further progress in his happiness and professional life.

\section{Case-2:}

Ram 33 male, diploma in engineering, could not focus on his work, and he was dismissed after 13 years of service in a public limited company. He presented with symptoms of depression lasting for eighteen months and unemployed for eight months. He was having suicidal thoughts, and his BDI-II score was 42.

Nine days after the intervention, his symptoms had mostly disappeared and antidepressants had been discontinued. Sixteen days after intervention, his BDI-II score was five. Nearly 
fifteen months after intervention, a telephonic contact was made, he was employed and feeling normal.

\section{Case-3:}

Kishor 29 male studying in B Tech final year presented with excessive sleep and appetite, depression, lack of confidence, and inability to concentrate on studies. After spending eight years, his four-year B Tech was still incomplete. He was worried, as his next examinations were just a few weeks away. During previous years, he had consulted several psychiatrists, read many books, and attended a few self-improvement seminars. At the time of presentation, his BDI-II score was 31. He was not taking any psycho-pharmaceuticals.

After intervention, he had a quick improvement. At two weeks, his BDI-II score was twelve. He passed B Tech without any further failures. About three years after the intervention, he was telephonically contacted. He had also completed his MBA, and he was employed and hopeful of a good future.

\section{DISCUSSION AND CONCLUSIONS}

The outcome in severe depression is currently considered highly unsatisfactory. Most of them either commit suicide or continue to suffer for extended period of time. (Kiloh, Andrews, \& Neilson, 1988) Each of the above three cases, however, experienced a quick and sustained recovery that could be considered unbelievable and dramatic by today's standards.

MACI is a unique intervention targeting multiple activities (behaviours, thoughts, and feelings) of the individual. In this regard and in many other regards, multiple activities change intervention is vastly different that similar sounding multiple behaviour change intervention (Griffin et al., 2014) or multiple health behaviour change intervention. (Prochaska \& Prochaska, 2011)

Detailed comparison of MACI and psychotherapies is not the purpose of this paper. However, a brief remark can be made. During cognitive behaviour therapy, three levels of thinking are to be targeted in that order: negative automatic thoughts, rules for living, and core beliefs.(Kinsella \& Garland, 2008) However, MACI begins by tackling core beliefs and rules for living first, and that only can explain the rapidity of recovery and completion within few sessions. Case- 1 had total of 7 sessions, but case- 2 and 3 had only three sessions each.

"Lester Luborsky, the pioneering psychotherapy outcomes researcher, is famous for advancing the "Dodo Bird hypothesis." After years of compiling meta-analytic studies, he and his colleagues concluded that the contest for the most effective form of psychotherapy had finally been settled. As the Dodo Bird declared at the finish of a race in Alice in Wonderland, "Everybody has won and all must have prizes"." (Pollak, Pedulla, \& Siegel, 2014) In this scenario it is difficult to believe that MACI gives such exemplary results.

Subsequent research has also suggested that the particular intervention is often less important than "common factors," such as the strength of the therapeutic alliance and the client related factors, in predicting outcomes. (Duncan, Miller, \& Sparks, 2004; Horvath, Del Re, Flückiger, \& Symonds, 2011; Stiles, 2009; Tryon \& Winograd, 2011)

This must raise some doubt in our minds. Is there a possibility that the improvement in our cases was due to these common factors? This and many more questions need to be answered, 
mostly by further studies. Nevertheless, this intervention needs our attention, as this is the only intervention that claims to target our (multiple) activities.

\section{REFERENCES}

Duncan, B. L., Miller, S. D., \& Sparks, J. A. (2004). The Heroic Client: A Revolutionary Way to Improve Effectiveness Through Client-Directed, Outcome-Informed Therapy. San Francisco: Jossey Bass.

Griffin, S. J., Simmons, R. K., Prevost, A. T., Williams, K. M., Hardeman, W., Sutton, S., . . . Kinmonth, A. L. (2014). Multiple behaviour change intervention and outcomes in recently diagnosed type 2 diabetes: the ADDITION-Plus randomised controlled trial. Diabetologia, 57(7), 1308-1319. doi:10.1007/s00125-014-3236-6

Horvath, A., Del Re, A., Flückiger, C., \& Symonds, D. (2011). Alliance in individual psychotherapy. In J. C. Norcross (Ed.), Psychotherapy relationships that work (2nd ed.). New York: Oxford University Press.

Kiloh, L. G., Andrews, G., \& Neilson, M. (1988). The long-term outcome of depressive illness. Br J Psychiatry, 153, 752-757.

Kinsella, P., \& Garland, A. (2008). Cognitive behavioural therapy for mental health workers: a beginner's guide. East Sussex, England: Routledge.

Pollak, S. M., Pedulla, T., \& Siegel, R. D. (2014). Sitting Together: Essential Skills for Mindfulness-Based Psychotherapy. New York: The Guilford Press

Prochaska, J. J., \& Prochaska, J. O. (2011). A Review of Multiple Health Behavior Change Interventions for Primary Prevention. Am J Lifestyle Med, 5(3). doi:10.1177/1559827610391883

Stiles, W. B. (2009). Responsiveness as an Obstacle for Psychotherapy Outcome Research: It's Worse Than You Think. Clinical Psychology: Science and Practice, 16(1), 86-91. doi:10.1111/j.1468-2850.2009. 01148.x

Tryon, G. S., \& Winograd, G. (2011). Goal consensus and collaboration. In J. C. Norcross (Ed.), Psychotherapy relationships that work (2nd ed.). New York: Oxford University Press.

Notes: (1) Real names have not been used in these case studies. (2) Video evidence of these cases is available with the author.

\section{Acknowledgements}

The author appreciates all those who participated in the study and helped to facilitate the research process.

\section{Conflict of Interest}

The author declared no conflict of interest.

How to cite this article: A. Agarwal (2020). Multiple activities change intervention, a developing psychosocial tool for severe depression: initial report of cases. International Journal of Indian Psychology, 8(2), 867-870. DIP:18.01.102/20200802, DOI:10.25215/0802.102 


\section{Related scientific papers}

1. Agarwal, Atul. 2020. "Reorientation of Activities and Self-environment Integration (ROASEI): A New Theory of Human Activities.” PsyArXiv. July 18. doi:10.31234/osf.io/8xz5s.

2. Agarwal, Atul. 2020. "Reorientation of Activities and Self-environment Integration (roasei)-activities Further Explained, and Theory of Activities Compared with Theories of Needs." PsyArXiv. July 13. doi:10.31234/osf.io/dxtvh.

3. Agarwal, Atul. 2020. "Perspectives on Targeting Cardio-vascular Diseases Through Reorientation of Activities.” PsyArXiv. July 12. doi:10.31234/osf.io/3mc8b.

4. Agarwal, Atul. 2020. "Why Do We Need a Robust Theory of Activities?.” PsyArXiv. July 12. doi:10.31234/osf.io/fr2uy.

5. Agarwal A. Multiple activities change intervention, a developing psychosocial tool for severe depression: initial report of cases. International Journal of Indian Psychology. 2020;8(2):867-70. doi: 10.25215/0802.102. Available from: https://ijip.in/wp-content/uploads/2020/06/18.01.102.20200802.pdf 